\title{
SEJARAH DAN BAHASA FIGURATIF DALAM TRADISI KATOBA PADA MASYARAKAT MUNA
}

\author{
Hadirman
}

IAIN Manado

\begin{abstract}
Abstrak
Masyarakat Muna memiliki salah satu tradisi, yakni katoba. Secara historis, keberadaan tradisi katoba di Muna terkait dengan awal masuknya Islam di Muna pada 1629-1665 M, yakni masa pemeritahan La Ode Abdul Rahman (bergelar Sangia La Tugho). Sejak masa pemerintahan Sangi La Tugho, hingga saat ini perkembangan tradisi katoba masih cukup kuat karena telah melembaga dalam sistem kebudayaan Muna. Tradisi ini dilaksanakan pada anak yang berusia (7-11 tahun) yang dipandu oleh seorang imamu (imam) desa. Dalam proses pelaksanaan tradisi katoba terjadi interaksi verbal antara imamu dan anak. Interaksi verbal tersebut, selain tercermin melalui bahasa sehari-hari anak, hadir pula kemasan bahasa figuratif (figurative language). Pemakaian bahasa figuratif tersebut, selain untuk memudahkan pemahaman anak terhadap nasihat/pesan katoba yang disampaikan, juga untuk memberikan makna khusus atau efek tertentu.
\end{abstract}

Kata kunci: sejarah, bahasa figuratif, tradisi katoba, masyarakat Muna

The History and Figurative Language in Katoba Tradition of Muna People

The people of Muna has a tradition called Katoba. Historically, the existence of this tradition was related with the earlier penetration of Islam in Muna at 1629-1665 AD, during the ruling period of La Ode Abdul Rahman (titled Sangia La Tugho). Since the ruling period of Sangia La Tungo until today, the Katoba tradition has been growing stronger as it has institutionalised in the Muna Cultural System. The tradition is performed on to children aged 7 to 11 and guided by a village imam (imamu). During the procession, verbal interaction happens between the imamu and the child. The verbal interaction, while reflecting the child's everyday language, also shows occurances of figurative language expressions. The reason in using figurative language is to help children to better understand the messages and advices of Katoba and to give special meaning or certain effects.

Keywords: history, figurative language, Katoba tradition, the Muna people 


\section{A. Pendahuluan}

Kabupaten Muna merupakan salah satu kabupaten di Provinsi Sulawesi Tenggara. Kabupaten ini memiliki banyak peninggalam budaya warisan leluhur. Salah satunya adalah tradisi katoba yang dimanfaatkan pendukungnya untuk membentuk pribadi anak agar beradat dan berkarakter Islami.

Tradisi katoba berasal dari kata toba yang artinya 'tobat, insaf'. Katoba adalah ritual "tobat" keagamaan untuk anak yang berumur antara 7-11 tahun: diajarkan laranganlarangan yang harus dijauhi dan perbuatanperbuatan baik yang harus dilakukan oleh seorang imam Islam, disaksikan oleh keluarga maupun undangan. Ritual ritual katoba dilakukan sesudah seorang anak disunat atau dikhitan.

Pelaksanaan tradisi katoba selalu melibatkan dewan syarah/tokoh adat dan agama di Muna, yang saat ini dikenal dengan imamu (imam) desa.Tradisi katoba sampai sekarang masih tetap didukung dan dilestarikan karena dianggap masih memiliki peranan dalam kehidupan masyarakat Muna. Tujuan kegiatan tradisi katoba selain untuk melestarikan budaya leluhur, juga sebagai dakwah Islam. Masyarakat Muna yang mayoritas beragama Islam melaksanakan tradisi katoba karena dalam ajaran Islam mengutamakan taubat (toba) agar memiliki sifat-sifat perbuatan terpuji dan melakukan perbuatan yang menyelamatkan diri baik di dunia maupun di akhirat.

Tradisi ini dalam konteks historis dapat menjalankan fungsinya dalam tiga hal, yakni (1) fungsi wahana pemelihara sejarah, (2) pengingat (mnemomic device), dan (3) sebagai jembatan antara tradisi dan sejarah masyarakat itu sendiri. Keterbatasan referensi tentang sejarah masa lalu masyarakat Muna, tradisi katoba dapat dijadikan sebagai salah satu sumber untuk mengenal dan menelusuri sejarah perkembangan Islam di Muna. Lebih lanjut, teks/tuturan tradisi katoba memiliki kemungkinan untuk dikembangkan menjadi salah satu sumber untuk mengenal dan menelusuri jejek sejarah dan budaya daerah Muna. Dengan demikian, kesadaran tentang sejarah lokal dapat digerakkan untuk mempertahankan identitas, yang pada akhirnya dapat membangun ketahanan budaya masyarakat itu sendiri.

Sementara itu, dalam konteks linguistik, tradisi katoba menjadi alat masyarakat Muna untuk mengkonstruksi kebudayaan, kebahasaan, dan kekayaan nilai-nilai luhur para leluhurnya. Bahasa hadir sebagai media untuk menyampaikan nasihat-nasihat katoba kepada anak yang di-katoba oleh seorang imam desa. Bahasa yang digunakan tersebut adalah bahasa Muna, yang merupakan bahasa lingua franca masyarakat Muna baik di Muna maupun di perantauan. Pilihan bahasa Muna oleh imam tersebut, selain memakai bahasa yang dipakai sehari-hari juga menggunakan bahasa figuratif untuk menyampaikan efek dan makna tertentu. Oleh karena itu, artikel ini mendiskusikan muatan sejarah dan bahasa figuratif yang tercemin dalam tradisi katoba.

\section{B. Sejarah Munculnya Tradisi Katoba di Muna}

Pembicaraan tentang sejarah tradisi katoba berkaitan erat dengan awal mula masuknya Islam di Muna. Berdasarkan sebuah sumber tertulis bahwa Islam masuk di Muna sejak tahun 1527 pada masa pemerintahan Raja Muna VI, yakni Sugi Manuru. Pada masa pemerintahan Sugi Manuru ini, tradisi katoba belum dilaksanakan oleh masyarakat Muna. Sebagaimana faslafah Muna yang 
dikemukakan Sugi Manuru yang berbunyi "Nohansu-hansurana bhadha somano kono hansuru liwu; nohansu-hansuruana liwu somano kono hansurru adhati (Artinya: biar hancur badan asalkan jangan hancur negeri; biar hancur negeri asalkan jangan hancur adat)". Cuplikan falsafah di atas menggambarkan adat tetap berjalan dan bahkan menjadi peraturan tertinggi yang harus dijunjung. Kemudian pada masa pemerintahan La Ode Abdul Rahman (Sangia Latugho) yang memerintah tahun 1629-1665, falsafah tersebut ditambahkan, nohansuhansuru ana adhati sumanomo kono hansuru agama (biar hancur adat asalkan agama jangan hancur. Dari falsafah tersebut bahwa yang menjadi pedoman bagi masyarakat adalah agama (Islam).

Versi lain mengenai tradisi katoba bermula dan popular di Muna tidak terlepas dari kedatangan ulama Arab yang bernama Sayid Raba pada masa pemerintahan La Ode Abdul Rahman (Sangia Latugho) yang memerintah tahun 1629-1665. Ia datang untuk meningkatkan keimanan masyarakat terhadap agama Islam. Dia meningkatkan kapasitas lembagalembaga pendidikan yang telah ada dengan memasukkan fikih Islam dalam materi pendidikan norma, terutama setiap dia selesai melakukan khitanan atau kangkilo atau menyucikan diri dimulai dari pusat kerajaan hingga ke pelosok desa yang ada di Muna.

Mementum pelaksanaan tradisi katoba anak laki-laki dan perempuan yang sudah aqil balig diajarkan beberapa hal penting yang terkait penyucian diri dengan mengucapkan istighfar atau taubat (dotoba "mereka bertobat", bahasa Muna) yang dipandu oleh pegawai syarah atau orang yang dipandang tua. Mereka yang memimpin upacara katoba adalah yang memiliki ilmu tentang taubat (toba) serta bisa diteladani perilakunya dalam masyarakat. Menurut pandangan orang Muna bahwa katoba harus dilaksanakan bagi setiap orang yang menjelang dewasa karena tradisi ini merupakan proses pelampauan dari sifat kekanak-kanakan menuju pemikiran orang dewasa baik dalam konteks agama maupun adat- istiadat.

Bertolak dari pemahaman demikian dapatlah dikatakan bahwa sejarah awal mula tradisi katoba pada masyarakat Muna mengandung muatan sejarah terutama berkaitan dengan ihwal masuknya agama Islam di Pulau Muna yang dibawa oleh ahli agama yang berasal dari Arab, oleh masyarakat Muna dikenal dengan nama Saidi Raba. Orang Muna mengawali tradisi katoba akibat proses Islamisasi, kemudian berkembang menjadi ciri dan karakteristik orang Muna sebab proses pelaksanaannya merupakan proses akulturasi antara nilainilai keaslian Muna dan nilai-nilai Islam.

\section{Konsep, Proses, Syarat, dan Dasar Pelembagaan Tradisi Katoba}

\section{Konsep}

Katoba dalam bahasa Muna berasal dari atas morfem $k a$ - dan kata dasar toba. Morfem $k a$ - dalam bahasa Muna berarti (1) nominalisasi pada kata kerja (benda abstrak, alat, hasil), misalnya pada kata kaghosa 'kekuatan', kaharo 'sapu', (2) awalan pada kata sifat, misalnya sala kawanta 'celana panjang', (3) awalan pada verba, misalnya nekarato 'Dia datang dengan tiba-tiba), (4) dengan perulangan pada nomina: sesuatu yang kecil, misalnya kawale-wale 'Pondok yang kecil', dan (5) dengan perulangan pada kata sifat: agak, misalnya nokapongke-pongke 'Dia agak tuli'. Kata toba dalam bahasa Muna berarti (1) tobat, misalnya pogauno toba "bahasa 
tobat', (2) tobat, insaf misalnya notobamo, noangkafimo katangarino imamu 'Dia sudah insaf, ikut nasihat imam' (3) tidak ada (dalam bahasa kiasan), (4) tobatkan (suatu upacara keagamaan untuk anak yang berumur enam tahun: diajarkan semua larangan dan perbuatan baik oleh seorang imam disaksikan keluarga dan undangan), misalnya pada dongkilo anahi, dotobadamo 'Setelah sunat atau khitan barulah upacara tobat). Etimologi katoba di atas, sebenarnya katoba berkaitan dengan upacara 'tobat' itu.

Penulis lain yang menguraikan asal-usul katoba adalah La Ode Jaya menyatakan bahwa katoba secara etimologis berasal dari kata toba yang diserap dari bahasa Arab, yakni kata taubah (tobat). Pandangan filosofis orang Muna, muncul sebuah klaim bahwa anakanak yang belum dewasa (kira-kira usia 7-11 tahun) belum memiliki kemampuan memilah baik-buruk. Atas dasar inilah tradisi katoba menjadi suatu keharusan dilaksanakan pada anak yang akan memasuki usia dewasa.

Defenisi katoba berdasarkan penelusurun kepustakaan yang ada, pertama kali dikemukakan oleh J. Couvreur dalam bukunya yang berjudul Ethnografisch overzicht van Moena yang diterjemahkan Rene van den Berg berjudul Sejarah dan Kebudayaan Muna mendefenisikan katoba sebagai pesta pada waktu anak-anak diislamkan pada umur kira-kira sebelas tahun (11 tahun) atau hampir umur kedewasaan.

Pelaksanaan tradisi katoba pada masa kerajaan Muna, melibatkan pejabat agama (lakina agamai) yang mengajarkan empat hal penting dalam tradisi katoba yakni: (1) yang harus disesali, yaitu berdosa kepada Allah swt, Nabi, dan sesama manusia; (2) yang harus dihindari, yaitu berdosa kepada Allah swt, Nabi Muhammad, dan sesama manusia;
(3) yang harus diputuskan'/dilupakan, yakni dosa-dosa orang lain terhadap yaitu berdosa kepada Allah swt, Nabi, dan sesama manusia; dan (4) hak-hak milik orang lain yang tidak boleh diambil, dan bila telah terambil, harus dikembalikan (haku nahasi).

\section{Proses Pelaksanaan Tradisi Katoba}

Sebagaimana masyarakat pada umumnya, masyarakat Muna juga belajar dari mulut ke mulut tentang tradisi katoba. Akibatnya, dalam pelaksanaan katoba bisa saja berbedabeda di setiap kampung atau kelompok masyarakat. Imamu yang memandu upacara katoba berbeda-beda prosesnya tetapi sama-sama bertujuan mengajarkan dan memberitahukan anak yang di-katoba tentang hakikat taubat.

Proses pelaksanaan upacara katoba ada tahapan-tahapan tertentu yang harus dilaksanakan secara berurutan, yakni sebagai berikut.

1. Persiapan pelaksanaan upacara katoba. Misalnya, dimandikan dengan tujuan membersihkan daki secara lahiriah maupun batiniah agar memudahkan pemahaman nilai-nilai katoba.

2. Dirias dengan pakaian adat Muna, yaitu pakaian remaja baik laki-laki maupun perempuan dengan tujuan dalam proses penyumpahan disambut dengan pakaian kebesaran atau pakaian adat Muna. Terdapat perbedaan antara golongan dalam hal berpakaian. Pada golongan maradika, para anak laki-laki dihiasi dengan pakaian yang paling bagus, memakai pengikat kepala sama dengan yang dipakai lakina agama, serta memakai sebuah keris. Para anak perempuan berpakaian lengkap dengan perhiasan keluarga (apabila keluarga tidak memiliki perhiasan, maka 
dipinjam dari orang lain), wajah mereka dihiasi dengan bedak berwarna putih atau kuning muda, alis digunting rapi sehingga berbentuk sabit, rambut kepala dekat telinga dicukur sedikir, sedangkan di antara rambut kepala bagian depan diselipkan sebuah pena rambut terbuat dari emas atau perak lengka dengan perhisan kecil-kecil yang melambailamnai seperti daun-daun ohon yang tertupi angin bila mereka berjalan.

Proses pelaksanaan acara inti ritual katoba, yaitu:

a. Peserta yang di-katoba duduk bersila dengan memegang sehelai kain putih secara bersama-sama jika pesertanya lebih dari dengan tujuan bahwa kain putih sebagai isyarat kesucian bagi umat Islam dan menjadi semangat kebersamaan (solidarity) dari seluruh peserta untuk mencapai tujuan penyumpahan.

b. Pengucapan Istighfar, syarat tobat dan tingkah laku yang baik. Setelah itu, lalu mengikrarkan tobat kemudian mengucapkan dua kalimat syahadat mengikuti imam, seperti berikut.

c. Astaghfirullaahal adzim (3x) lalu dilanjutkan Allazii laa illaha illallah huwal hayyul qayuumu wa atuubbu illahi.

d. Pengucapan kalimat Tauhid setelah itu mengucapkan dua kalimat syahadat: Asyhadu an laa illaha illallah wa syahadu anna Muhammadar rasulullah. "Saya bersaksi bahwa tidak ada Tuhan yang disembah selain Allah dan saya bersaksi pula bahwa Muhammad adalah utusan Allah".

e. Pemberian pengajaran (nasihat) katoba.
Proses pelaksanaan tradisi katoba ada beberapa hal pokok yang menjadi penting untuk dihayati dan diamalkan oleh peserta katoba dalam kehidupannya, karena menjadi dasar mempedomani ajaran agama Islam. Substansi ajaran taubat dalam katoba adalah: 1. Mengucapkan kalimat istighfar, yaitu ucapan awal yang harus diucapkan oleh peserta katoba. Ucapan ini mengandung maksud sebagai proses pembersihan diri baik secara lahiriah maupun batiniah;

2. Pengucapan ikrar kalimat tauhid dan kalimat rasul;

3. Ikrar tentang penyesalan (ososo)'

4. Ikrar tentang pernyataan sikap untuk tidak mengulangi lagi perbuatan yang dianggap bertentangan dengan ajaran agama (obhotuki);

5. Penyataan sikap dan moral untuk menjauhi perbuatan yang bertentangan dengan ajaran agama (fekakodoho);

6. Pengkuan untuk menaati perempuan dan laki-laki, baik orang tuanya sendiri maupun orang tua lain yang dianggap sama kedudukannya dengan orang tua sendiri;

7. Menghargai, menyayangi, menyegani, dan menghormati kakak dan adik, baik kakak dan adik sendiri maupun dengan semur dengan mereka;

8. Pengakuan untuk memiliki dan melaksanakan sifat-sifat; koemani (beriman), kosabara (sabar), koadhati (beradat) dalam menjalani kehidupan sehari-hari sebagai dasar utama menguasai diri dan mengontrol emosi untuk mewujudkan kehidupan yang harmonis.

Berdasarkan uraian di atas semakin memperjelas eksistensi tradisi katoba sebagai pedoman hidup yang apabila dipahami dan 
diamalkan dengan baik dalam kehidupan sehari-hari mengantarkan manusia untuk selamat di dunia dan di akhirat. Nasihat yang terdapat dalam tradisi katoba mengajarkan tentang perilaku dalam kehidupan bermasyarakat. Oleh karena itu, bila seseorang telah mengalami pendidikan dalam tradisi katoba maka orang tersebut sudah mengetahui perilaku-perilaku yang sesuai dengan ketentuan adat dan agama Islam.

\section{Syarat-Syarat Tradisi Katoba}

Syarat-syarat katoba dalam konstruksi kebudayaan masyarakat Muna Muna agar diterima oleh Allah swt diformulasikan sebagai berikut.

1) Tososo,yaknimenyesaliatasperbuatan dosa yang pernah dilakukan, artinya bahwa dalam proses katoba, maka salah satu persyaratan yang harus dilakukan adalah peserta yang ditaubat harus komitmen moral untuk menyesali seluruh perbuatan dosa yang tidak disengaja.

2) Tobhotuki, yakni menyucikan diri/ mencabut perbuatan maksiat yang sudah dilakukan, bahwa seseorang yang ditaubat melafalkan kalimat istighfar sebagai syarat bahwa dia menyucikan diri dari perbuatan dosa baik yang sifatnya sirik maupun perbuatan maksiat yang pada masa kecil dilakukan. Ikrar ini dilafalkan oleh seseorang yang ditaubat dengan harapan bahwa ketika telah melewati proses katoba, maka kembali pada status kefitraannya.

3) Bertekat bulat tidak akan mengulanginya lagi, artinya bahwa untuk melakukan dua hal yang telah dijelaskan di atas, maka harus diawali dengan niat tulus dan ikhlas untuk tidak melakukan hal-hal yang dapat mengakibatkan perbuatan dosa. Dalam konteks penyesalan dan penyucian diri bahwa untuk mencapai kedua hal tersebut, maka yang menjadi kuncinya adalah tekad yang dilandasi niat. Dalam bahasa Muna, Nobhala neati bhe podiu rampahamo podiu nomaighi welo neati 'Besar manfaat niat daripada tingkahlaku, karena tingkah laku berawal dari niat".

Tiga syarat katoba tersebut di atas tidak saja selalu mengiringi setiap taubat dari kejahatan yang berhubungan antara manusia dengan Tuhan-Nya saja akan tetapi jika perbuatan itu dihubungkan dengan manusia maka selain tiga syarat tobat tersebut diwajibkan pula memenuhi syarat keempat, yaitu tindakan penyelesaikan dengan orang yang bersangkutan.

Berdasarkan uraian di atas, tradisi katoba pada masyarakat Muna merupakan kontekstualisai ajaran Islam. Buku Hakikat Taubat tulisan Imam al-Ghazali, maka jelas sekali kaitan antara nasihat katoba masyarakat Muna dengan perihal taubat dalam ajaran Islam. Barometer keterkaitan ajaran katoba dengan ajaran Islam perihal taubat sejalan dengan firman Allah dalam al-Quran dan sabda dalam hadits Nabi Muhammad saw.

Perintah taubat dalam al-Quran surat An-Nisa ayat 31, Surat At-Thamrin ayat 8, menyuruh manusia bertobat dengan sebenarbenarnya, karena manusia semuanya berdosa, dan meminta ampun semoga Allah swt memberikan kesempatan untuk memasuki surga-Nya. Sabda Nabi Muhammad saw yang diriwayatkan oleh Bukhari dari Ibnu 
Umar, berkata "Alkabaairu al israaku billahi, wa aqququl walidaini, waqatlun nafsi, walyamiinul ghamuusu" artinya dosa besar yaitu: 1) menyerikatkan Allah, 2) durhaka keadaa kedua orang tua, 3) membunuh manusia, dan 4) bersumpah palsu.

Imam Al-Ghazali menguraikan syarat tobat ada empat, yaitu tiga dari Allah dan satu kepada manusia, yakni: (1) menyesal, yaitu menyesali perbuatan sebelumnya yang tidak benar; (2) meniadakan/menyucikan, artinya menyucikan atau meniadakan diri dari perbuatan dosa; dan (3) memutuskan, yaitu bertekat kuat untuk tidak akan menguangi perbuatan yang tidak baik.

Tradisi katoba di samping sebagai media menyampaikan pesan moral dan etika pada anak yang ditaubat, juga merupakan upaya melegitimasi ke-Islam-man seorang anak di Muna. Dalam tradisi lisan katoba pejabat agama mengingatkan beberapa perintah agama yang penting, yakni (1) yang harus disesali, yaitu berdosa kepada Allah, nabi Muhammad, dan sesama manusia; (2) yang harus dihindari, yaitu berdosa kepada Allah, nabi Muhammad, dan sesama manusia; (3) yang harus diputuskan/dilupakan, yatu berdosa kepada Allah, nabi Muhammad, dan sesama manusia; dan (4) hak atau miliki orang lain yang tidak boleh diambil dan bila telah diambil, harus dikembalikan (haku nahasi).

\section{Dasar Pelembagaan Tradisi Katoba}

Perkembangan konsep-konsep dasar tradisi budaya dan dalam perkembangannya dari generasi ke generasi pada masyarakat tradisional di masa silam, ada dua faktor yang dominan berpengaruh, yaitu 1) faktor kepercayaan dan keyakinan agama masyarakatnya, dan (2) faktor legalisasi kekuasaan an sistem pemerintahan (kerajaan/kesultanan).
Faktor kepercayaan dan keyakinan agama yang dianut masyarakatnya, berfungsi menanamkan nilai-nilai dan norma-norma kesakralan atau kesucian terhadap konsep ajaran yang tertuang dalam bentuk tradisi budayanya. Sedangkan dari faktor legalisasi kekuasaan dan sistem pemerintahan kerajaan/kesultanan di masa silam, berfungsi menanamkan nilai-nilai dan norma-norma kekuatan pemaksa terhadap suatu bentuk tradisi budaya dan selanjutya berfungsi sebagai penguat dan pengawal dalam proses perkembangan (pemasyarakatan dan pembudayaannya).

Proses pembentukan dan perkembangan tradisi, budaya masyarakat Muna nilai-nilai dan norma-norma masih diwarisi hingga saat ini dengan merujuk pada (1) pengaruh keyakinan agama masyarakat Muna pada masa silam, dan (2) legalisasi kekuasaan dari sistem pemerintahan kerajaan Muna ketika itu. Proses pembentukan konsep-konsep dasar tradisi budaya Muna dalam bentukbentuk adat-istiadatnya adalah sebagai berikut.

1) Konsep dasar budaya Muna dibentuk oleh pengaruh agama dan sistem pemerintahan kerajaan Muna pra-Islam. Bentuk-bentuk kebudayaan Muna, dapat diamati dalam tata cara pelaksanaan katingka dan kaago-ago serta pahampaham animisme lainnya, yang masih dipengaruhi sistem kehidupan sosial masyarakat Muna hingga saat ini.

2) Konsep dasar tradisi budaya Muna yang dibentuk oleh hasil persenyawaan antara pengaruh agama pra-Islam dan ajaran Islam. Seperti adat kaghombo/karia, kagaa (perkawinan) dan adat kasambu (suapan), serta konsep stratifikasi sosial masyarakat. 
3) Konsepdasar tradisibudaya Munayang dibentuk oleh pengaruh ajaran Islam. Seperti adat kangkilo/katoba, pola dan upacara peringatan bulan-bulan tertentu, menurut perhitungan tahun Hijriyah. Misalnya, peringatan Maulid Nabi Muhammad pada bulan radhabu (rabiul awal), mengirimkan (membacakan) al-Fatiha, al-Ikhlas, tahlil, dan kepada roh para orang tua dan anak-anak keluarga kaum muslimin dan muslimat yang telah meninggal dunia, pada setiap bulan Rajab. Atau peringatan basahae sifu (Nifsu Saban) di bulan Saban, yaitu membacakan surat Yasin 3 kali dan doa Nisfu Saban setiap kalinya, dengan niat memohon umur yang panjang rejeki yang melimpah dan halal, iman yang kuat, untuk bekal ibdah keada Allah swt. Peringatan 1 Ramadhan, Idul Fitri dan Idul Adha ada 1 Syawal dan 10 Julhijah dan sebagainya.

\section{Proses Pelembagaan Tradisi Budaya Muna}

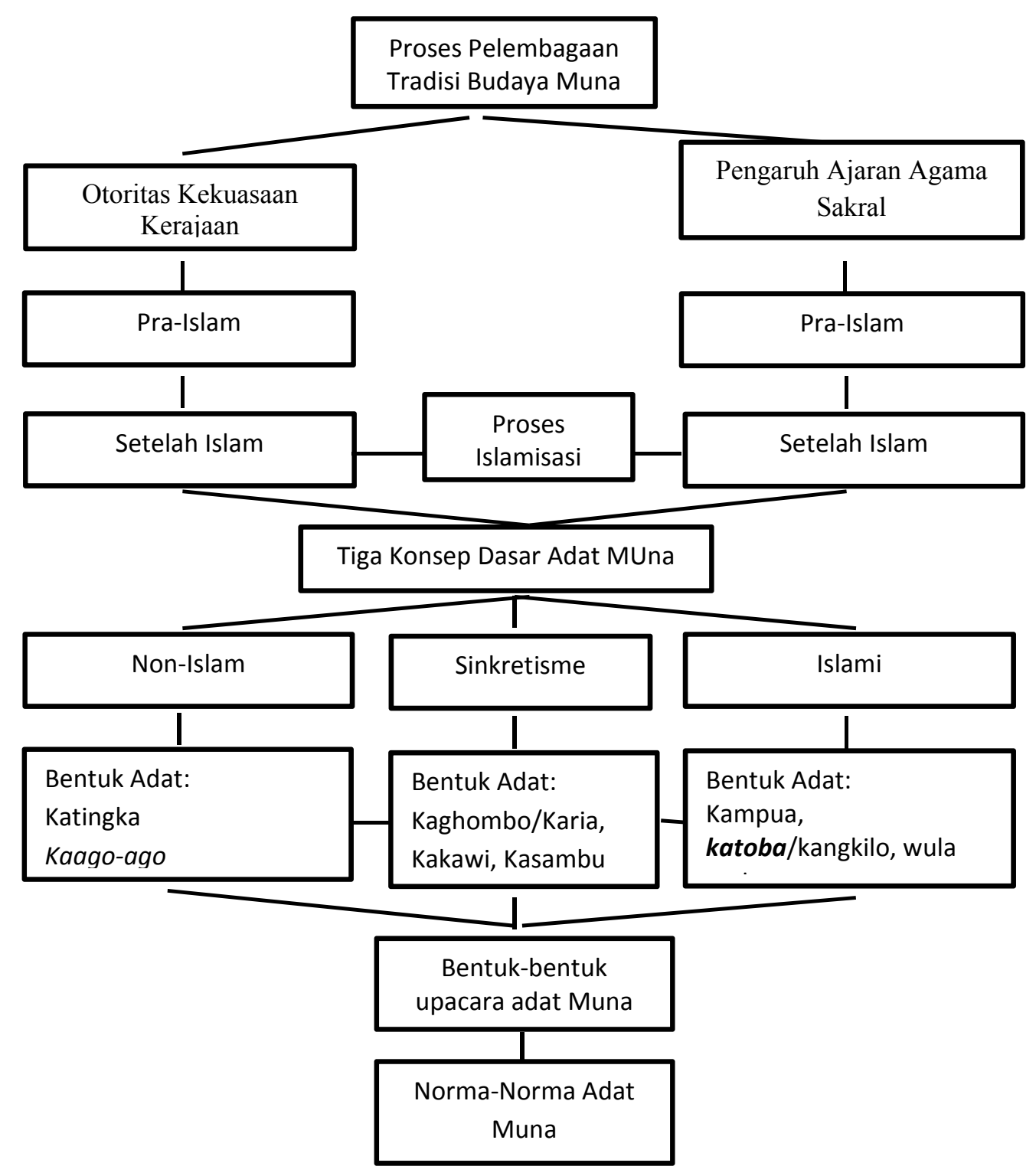

Bagan 1: Proses PelembagaanTradisi Budaya Muna ${ }^{1}$

Lutfi Muh. Malik, Islam dalam Budaya Muna: Suatu Ikhtiar Menatap Masa Depan (Ujung Pandang: PT Umitoha Ukhuwah Grafika, 1997). 
Berdasarkan bagan 1 di atas, semakin memperjelas bahwa tradisi katoba atau ritual "taubat" merupakan tradisi yang berakar pada Islam. Katoba, selain memperlihatkan ciri ketradisian juga memperlihatkan ciri kelisanan. Tradisi katoba mengungkapkan hal-hal penting yang berkenaan dengan transmisi nilai-nilai agama Islam dan kearifan lokal dalam lingkungan keluarga, khususnya bagi anak-anak yang beranjak dewasa untuk menjalani hidup dikemudian hari kelak.

\section{Bahasa Figuratif yang Tercermin dalam Tradisi Katoba}

Pelaksanaan tradisi katoba bertujuan positif. ${ }^{2}$ Salah satu carauntukmengidentifikasi tujuan positif tersebut adalah dengan melihat makna budaya yang tercermin melalui bahasa yang digunakan dalam tuturan tradisi katoba. Bahasa figuratif atau kiasan merupakan penyimpangan dari bahasa yang digunakan sehari-hari (ordinary), menyimpang dari bahasa baku atau standar, penyimpangan makna dan penyimpanan susunan (rangkaian) kata-kata supaya memperoleh efek atau makna khusus. Bahasa figuratif terdiri atas simile, metafora, metomini, sinekdoke, dan personifikasi. ${ }^{3}$ Bahasa figuratif yang digunakan untuk mengidentifikasi tuturan katoba, setidak-tidaknya melalui pemahaman budaya yang merupakan latar pemakaian tuturan ritual tersebut.

Tradisi katoba sebagai sebuah ritual, memiliki bahasa yang khas. Bahasa ritual secara khas berbeda dengan bahasa seharihari (ordinary language). Bahasa ritual salah satunya lebih menekankan pada pemakaian

Pengertian positif di sini adalah pelaksanaan tradisi lisan katoba serta kaitannya dengan yang lain memiliki tujuan baik. Hal ini lepas dari pandangan dari kelompok atau masyarakat tertentu. M.H Abrams, A Glossay of Literacy Terms, (New York: Holt Rinehart and Winston, 1981) hlm.63. bahasa figuratif. ${ }^{4}$ Bahasa yang digunakan dalamtuturan ritualmemiliki "penyimpangan" dalam pemakaian. Penyimpangan tersebut merupakan kekhasan ekspresi yang menegaskan sifat dan fungsi bahasa ritual. Dengan demikian, pemahaman terhadap tuturan ritual selalu dikaitkan dengan bentuk dan acuan yang bersifat menyimpang. ${ }^{5}$

Bahasa figuratif berfungsi sebagai alat untuk memperkuat efek atau membuat pendengar terkesan terhadap gagasan yang disampaikan. Bahasa figuratif digunakan oleh imamu untuk mengungkapkan pikiran agar lebih efektif dan tercapai maksud pesan yang ingin disampaikan. Berdasarkan data ungkapan dalam tradisi katoba ditemukan dua bentuk bahasa figuratif, yakni (1) simile dan (2) metafora. Kedua bentuk bahasa figuratif tersebut, digunakan oleh imamu sebagi bentuk komunikasi efektif kepada anak yang di-katoba dijelaskan sebagai berikut.

\section{1) Simile}

Simile adalah perbandingan yang bersifat eksplisit. ${ }^{6}$ Simile dapat disebut sebagai perumpamaan atau perbandingan. Biasanya, simile menyamakan satu hal dengan hal lain dengan menggunakan kata perangkai seperti, sebagai, bagai, bak, dan kata-kata lain yang dapat disamakan dengannya. Artinya, di dalam simile itu terdapat perbandingan antara dua objek atau benda yang berbeda jenis, tetapi memiliki kesamaan. Kesamaan dilihat dari fitur semantis kedua objek atau benda yang diperbandingkan. Penanda simile dalam bahasa Muna, khususnya yang digunakan dalam tradisi katoba adalah peda

James J. Fox, Bahasa, Sastra dan Sejarah: Kumpulan Karangan Mengenai Masyarakat Pulau Roti, (Jakarta: Penerbit Djambatan (Seri ILDEP), 1986).

Ibid.

Gorys, Keraf, Diksi dan Gaya Bahasa, (Jakarta: PT Gramedia Pustaka Utama, 2007), hlm. 138. 
adhono 'seperti', lansaringino 'ibaratnya', folumo 'bagaikan', ibara 'ibarat'. Hal ini dapat dicermati pada data berikut ini.

[1] (1) Amando dotehie fulumo kabholosino Allah Taala. (2) Inando dotehie folumo kabholosino anabi Muhamadhi. (3) Isando dotehie fulumo kabholosino malaekati. (4) Aindo doasiane fulumo kabholosino o mukmini '(1) Bapak kalian takutilah bagaikan penggantinya Allah Ta'ala. (2) Ibu kalian takutilah karena ibu bagaikan penggantinya nabi Muhammad. (3) Kakak kalian takutilah karena kakak bagaikan penggantinya malaikat. (4) Adik kalian sayangilah karena adik bagaikan pengganti kaum mukmin'

Mencermati contoh [1] di atas, tampak bahwa imamu menggunakan bentuk simile folumo 'bagaikan' untuk menjelaskan keterkaitan antara manusia dengan simbol-simbol agama. Leksikon ama 'bapak', ina 'ibu', isa 'kakak' dan ai 'adik' menunjukkan sapaan kekerabatan, sekaligus leksikon tersebut menunjukkan manusia. Sementara itu, leksikon dan frasa-frasa, seperti Allah Taala 'Allah swt', anabi Muhammadhi 'nabi Muhammad', malaekati 'malaikat', dan o mukmini 'mukmin' dengan manggambarkan hal-hal yang berkaitan dengan ranah agama Islam.

Secara figuratif, bahasa katoba di atas perumpamaan antara ama 'ayah' dan Allah Taala 'Allah Taala" digunakan untuk memudahkan pemahaman anak terhadap nasihat katoba, serta hanya didasarkan pada peran yang diemban dan persamaan tentang fitur semantik ama 'ayah' [+ tempat meminta anak], dan Allah Taala 'Allah Taala' [+ tempatmeminta manusia]. Kata ina 'ibu' diumpamakan sama dengan anabi Muhamadhi 'Nabi Muhammad' karena didasarkan pula pada peran dan kesamaan fitur semantis ina 'ibu' [+ mendidik anak] dan anabi Muhamadhi 'Nabi Muhammad' [+ mendidik umatnya]. Kata isa 'kakak' diumpamakan sama dengan malaekati 'malaikat' semata-mata didasarkan pula pada peran yang diemban. Isa 'kakak' memiliki fitur semantis [+ ditugasi ayah untuk menjaga atau mengawasi ai 'adik'] dan malaekati 'malaikat' [+ diperintah atau ditugasi Allah Ta'ala 'Allah Ta'ala' untuk mengawasi umat manusia]. Kata ai 'adik' diumpamakan pula dalam bahasa katoba dengan o muumini 'mukmin' karena didasarkan pada peran yang diemban ai 'adik' yang harus disayangi [ + disayangi], demikian pula o muumini 'mukmin' [+ harus disayangi, menyayangi].

Hadirnya bentuk simile folumo 'bagaikan' pada ungkapan [1] (1-4) di atas adalah memudahkan anak untuk mengenal lebih dekat Tuhan-Nya sekaligus mengajarkan kepada anak untuk menghargai kedudukan ayah kandung sebagai orang yang harus dihormati dan diteladani dalam rumah tangga. Sebagai seorang anak sepantasnya takut kepada setiap larangannya, patuh dan tunduk terhadap segala perintahnya yang sesuai ajaran agama, dan wajib menghormati orang tuanya. Kebiasaan patuh dan taat pada kedua orang tua dalam lingkungan keluarga selanjutnya wajib bagi sang anak untuk dipraktikkan dalam kehidupan bermasyarakat, bukan saja bapak kandung yang harus ditakuti atau dihormati, tetapi berlaku bagi semua laki-laki yang telah berstatus sebagai orang tua.

Pemaknaan dari nasihat katoba pada data [1] yakni: ayah bukanlah pengganti Allah melainkan sebagai sosok yang merepresentasikan sifat Ketuhanan (sifat Illahiyah) dalam keluarga. Demikian halnya dengan seorang ibu atau kakak, mereka bukanlah pengganti nabi dan atau malaikat tapi sebagai sosok 
yang merepresentasikan sifat kenabian dan kemalaikatan dalam lingkungan keluarga. Demikian pula halnya dengan seorang adik harus disayangi dan dibina, karena dalam ajaran Islam menggambarkan sesama kaum mukmin diwajibkan untuk saling mengasihi dan menyayangi. ${ }^{7}$

Selain penggunaan bentuk simile folumo 'bagaikan' seperti pada ungkapan [1] di atas, dalam tuturan katoba ditemukan pula bentuk simile pedha adhono 'seperti'. Penggunaan bentuk simile pedha adhono tampak pada tuturan [2] di bawah ini.

[1] (1) o guru itu anoa pedha andono kamokulanto, taaka o guru lumiuno kamokulanto rampano o guru fotusughoono kangkaha metaano. (2)Dadi ane mentaleahano nobhala guru bhe kamokula. (3) Morondohano pototo bhe kamokula. (4) Ane namate gurumu bhe kamokulamu nasegholeo maka kala deki kanthobha gurumu maka suli kantobha kamokulamu.

'(1) Guru itu sama seperti orang tua kita, tetapi guru lebih dari orang tua kita karena guru yang menunjukkan jalan yang baik. (2) Jadi, yang lebih terang, lebih besar guru daripada orang tua. (3) Yang lebih gelap sama dengan orang tua. (4) Kalau gurumu dan orang tuamu meninggal dalam waktu yang bersamaan, pulanglah kuburkan gurumu terlebih dahulu, setelah itu kuburkan pulalah orang tuamu"

Tuturan [2] menunjukkan bahwa seorang imamu memberikan penjelasan tentang kedudukan guru dan orang tua dengan memanfaatkan bahasa figuratif berjenis simile pedha

Asriani, "Nilai Pendidikan Karaker dalam Tuturan Katoba di Muna", Tesis. (Gorontalo:Universias Negeri Gorontalo, 2014) dalam http://eprints.ung.ac.id/63/ diakses 30 Mei 2017 andono 'seperti'. Bentuk bahasa figuratif simile ini digunakan untuk memberikan efek makna pada tuturan yang disampaikan. Melalui penyampaian pesan dengan bentuk simile ini, akan mudah memberikan pemahaman pada anak mengenai kedudukan seorang guru kepada anak. Hadirnya, penanda simile pedaha adhono 'seperti' menunjukkan bahwa peran dan jasa guru yang mulia itu, memiliki kedudukan yang sama, bahkan lebih mulia kedudukannya bila dilihat dari sudut pandang pendidikan formal (sekolah) bila dibandingkan dengan orang tua kandung anak.

Pemberian predikat "sama" itu tercipta dari analogi kekerabatan, yakni peran guru sama dengan orang tua yang memberikan pendidikan untuk masa depan anak. Kesamaan itu dapat diformulasi dalam fitur semantis, yakni o kamokula 'orang tua' [+ membesarkan dan membentuk karakter anak dalam lingkungan keluarga; pendidikan non-formal] dan o guru 'guru' [+ membesarkan dan membentuk karakter anak dalam lingkungan pendidikan sekolah; pendidikan formal]. Masyarakat Muna menempatkan guru pada posisi tertinggi. Guru mengajarkan ilmu dan melatih anak dengan sabar dan penuh "kasih sayang".

Seorang guru menduduki posisi penting dalam bahasa katoba dibandingkan dengan orang tua kandung anakyang di-katoba karena guru adalah pendidik di dalam pendidikan formal. Pendidikan di sekolah ilmu tidak diperoleh begitu saja tetapi melalui proses pembelajaran yang melibatkan peran sentral guru. Seorang guru mempunyai peranan yang sangat besar dalam membentuk karakter dan kepribadian. Seorang guru mengajarkan berbagai macam ilmu pengetahuan maupun keterampilan yang sangat penting bagi 
masa depan anak-anak. Oleh karena itu, selayaknyalah jika kita bersikap baik terhadap para pendidik.

Hal ini semakin memperkuat asumsi, bahwa guru merupakan insan yang paling utama dalam proses pendidikan formal. Oleh karena itu, sudah sepantasnyalah guru harus dihormati dan dihargai dengan penuh dedikasi dan ketulusan yang mendalam. Seperti diungkapkan diawal tadi, bahwa guru adalah penunjuk jalan yang benar, maka ia harus dimuliakan dan dihargai.

\section{2) Metafora}

Tuturan ritual sering memanfaatkan metafora. Pemanfaatan metafora ini dapat membangun makna tertentu, yang menjadikan tuturan ritual berkarisma dan bertuah. ${ }^{8}$ Penggunaan metafora menjadikan arti yang dimaksudkan menyimpang dari arti leksikal sehingga menciptakan kekaburan. Kekaburan itu memberi tempat bagi konteks budaya dalam memaknai bahasa ritual.

Metafora digunakan sebagai sarana pengungkapan ide. Setiap pemakaian bahasa adalah juga metafora meskipun diakuinya pula bahwa menurut pandangan lama, metafora memiliki dan memberikan efek makna khusus. Setiap proses pemilihan kata beserta cara-cara penyusunannya agar pemberian makna sesuai dengan yang dikehendaki merupakan bagian dari metafora. ${ }^{9}$

Metafora adalah semacam analogi yang membandingkan dua hal secara langsung, tetapi dalam bentuk singkat: bunga bangsa, buaya darat, buha hati, cindera mata, dan sebagainya. ${ }^{10}$ Metafora sebagai pembanding

8 Soepomo Poedjosudarmo, Filsafat Bahasa (Surakarta: Universitas Muhammadiyah Press, 2001), hlm. 160

9 A.P. Martinich, 1996. The Philosophy of Language (Third edition), (Oxfrod: Oxfrod University Press, 1996).

10 Gorys Keraf, Diksi dan Gaya Bahasa, (Jakarta: PT Gramedia Pustaka Utama, 2017), hlm. 139 langsung tidak mempergunakan kata: seperti, bak, bagai, laksana, dan sebagainya, sehingg pokok pertamalangsung dihubungkan dengan pokok kedua. Proses terjadinya sebenarnya sama dengan simile tetapi berangsur-angsur keterangan mengenai persamaan dan pokok utama dihilangkan.

Secara implisit metafora adalah perbandingan tanpa penanda simile. Metafora bisa dikatakan sebagai analogi atau kias. Ungkapan metaforis mengalami pemindahan fitur semantis dari makna lateral ke makna nonlateral. Dalam bahasa katoba terdapat bagian yang mengandung metafora. Simbol-simbol berupa flora atau fauna ataupun bendabenda alam yang dianggap seperti manusia. Berdasarkan data tuturan tradisi katoba yang ada, diketahui bahwa proses metafora melukiskan interaksi aspek-aspek yang meliputi: manusia dan tumbuhan-tumbuhan yang hidup di lingkungan masyarakat Muna. Secara konkret hubungan dari berbagai unsur tersebut dapat dilihat dalam ekspresi tuturan katoba berikut.

[3] (1) Ane owora kokarawuno ghofano koe seliea atawa koe meuta ne kobhakeno palolano atawa kogholeno labuno koe findahiea. (2) Ane gholeno labu nopolobhighoo kangkaha fopalie gholeno, koe findahiea. (3) Karawuno ghofa, bhakeno palola, gholeno labu ainiini maanano hakuno manusia bhe nehakuno Allah Taala. (4) Ane padamu otolimpapa ne manikamu, haku nehakuno Allah Taala, maka mesaloanemo amponi ne wutono Allah Taala.

(1) Kalau melihat timbunan ubi talas orang lain, jangan kamu gali atau jangan kamu memetik terung orang lain atau jangan 
menginjak pucuk daun labu orang lain. (2) Kalau pucuk daun labu membentang di jalan, kamu pindahkan pucuknya, jangan kamu injak. (3) Timbunan ubi talas, buah terung, pucuk daun labu tadi, maknanya haknya manusia yang menjadi hak Allah Taala. (4) Kalau sudah bersalah pada manikam, hak yang menjadi hak Allah, maka memohon ampunlah pada Allah'.

Ungkapan [3] di atas terdiri atas frasa kokarawuno ghofano 'yang bertimbunan ubi talas', kobhakeno palolano 'yang berbuah terung', dan kogholeno labuno 'yang berpucuk daun labu' yang merupakan frasa nomina (benda).Frasakokarawuno'yangbertimbunan' menerangkan ghofa 'ubi talas'; frasa bhakeno 'buahnya' menerangkan palola 'terung'; frasa gholeno 'pucuknya' menerangkan labu 'labu'. Ungkapan-ungkapan karawuno ghofa 'timbunan ubi talas', bhakeno palola 'buah terung', dan gholeno labu 'daun labu' merupakan metafora, yakni menerangkan perilaku manusia.

Timbunan ubi talas, buah terung, dan pucuk daun labu adalah tanaman. Tanaman yang menjadi milik orang lain tidak boleh diganggu atau diambil. Dengan demikian, frasa karawuno ghofa 'timbunan ubi talas' mengacu pada manusia khususnya, yakni wanita (istri) orang lain. Frasa bhakeno palola 'buah terung' dan gholeno labu 'pucuk daun labu' mengacu pada manusia khususnya laki-laki (suami) orang lain. Nasihat katoba di atas mengajarkan kepada anak (lakilaki/perempuan) setelah dewasa dan telah menikah tidak diperbolehkan mengganggu suami atau istri orang lain. Dengan kalimat lain, ungkapan [3] secara lateral bermakna larangan menginjak karawuno ghofa 'timbunan ubi talas', bhakeno palola 'buah terung' dan gholeno labu 'pucuk daun labu' miliki orang lain. Akan tetapi, secara nonlateral sebenarnya mengandung makna larangan berzina dengan suami/istri orang lain. ${ }^{11}$

\section{E. Penutup}

Secara historis tradisi katoba merupakan tradisi masyarakat Muna yang ada dan popular dilaksanakan sebagai sebuah praktik budaya setelah masuknya ajaran Islam di Muna. Setelah masuknya agama Islam di wilayah Muna, serta pada saat pemerintahan Raja Muna La Ode Abdul Rahman (Sangia Latugho) yang tahun (1629-1665), tradisi ini mulai dilaksanakan dengan perpaduan antara kepercayaan leluhur dengan ajaran Islam. Meskipun zaman telah berubah, keberadaan tradisi katoba hingga saat ini, masih bertahan dan dipraktikkan oleh masyarakat Muna.

Pelaksanaan tradisi katoba peran dewan syarah/agama atau imam (imamu) desa saat ini, sangat sentral dalam tradisi katoba. Pelaksanaan tradisi ini, sarat dengan pesanpesan positif, sehingga untuk menyampaikan pesan itu kepada seorang anak, seorang penyampai (imam) haruslah memiliki kompentensi bahasa, terutama bahasa yang mudah dipahami anak. Penyampaian pesan melalui tuturan tradisi katoba, seorang imam memanfaatkan bahasa figuratif. Penggunaan bahasa figuratif dimaksudkan untuk menjelaskan makna yang lain, dengan memberikan analogi-anaogi sehingga anak dapat memahami dengan mudah terhadap nasihat katoba yang diajarkan. Penggunaan bahasa figuratif dalam penyampai pesan dalam tradisi katoba

Ardianto dan Hadirman, "Tindak Tutur Direktif Imamu Berbasis Kearifan Lokal dalam Wacana Katoba pada Guyup Tutur Etnik Muna". Proceeding Simposium Internasional Islam and Local Wisdom, Kendari, Sulawesi Tenggara, Tanggal 25-26 April 2017. 
pada masyarakat Muna terdiri atas dua bentuk yakni (1) simile dan (2) metafoa.

\section{DAFTAR PUSTAKA}

Abrams, M.H. A Glossay of Literacy Terms, (New York: Holt Rinehart and Winston, 1981).

Ardianto dan Hadirman, "Bahasa Muna sebagai

Penguat Identitas Kultural Komunitas

Muna dan Penyanggah Harmoni Sosial pada Masyarakat Multikultural di Kota Bitung", Prosiding Seminar Bahasa Ibu, Depnasar 24-25 Februari 2017, dalam https://www.researchgate.net/ publication/ diakses 30 Mei 2017

--------, “Tindak Tutur Direktif Imamu

Berbasis Kearifan Lokal dalam Wacana

Katoba pada Guyup Tutur Etnik Muna".

Proceeding Simposium Internasional

Islam and Local Wisdom, Kendari, Sulawesi Tenggara, Tanggal 25-26 April 2017.

Asriani, "Nilai Pendidikan Karaker dalam Tuturan Katoba di Muna", Tesis. (Gorontalo: Universias Negeri Gorontalo, 2014) dalam http://eprints.ung. ac.id/63/ diakses 30 Mei 2017.

Berg, Rene van den \& Sidu Marafad, Kamus Muna-Indonesia, (Kupang: Artha Wacana Press, 2000).

Couvreur, Couvreur, Sejarah dan Kebudayan

Kerajaan Muna, diterjemahkan oleh Rene van den Berg, dengan judul asli Ethnografisch overzict van Moena (Kupang: Artha Wacana, 2001) .

Fox, James J., Bahasa, Sastra dan Sejarah: Kumpulan Karangan Mengenai Masyarakat Pulau Roti, (Jakarta: Penerbit Djambatan (Seri ILDEP), 1986).
Hadirman, "Tradisi Katoba sebagai Media Komunikasi Tradisional Masyarakat Muna", dalam Jurnal Komunikasi dan Opini Publik, Vol. 20 No. 1, Agustus 2016:11-30 (Manado: BPPKI Manado, 2016).

Kadir, dkk. Muatan Lokal, Nilai-Nilai Kebudayaan dan Sejarah Daerah Kabupaten Muna, (Muna: Dinas Pendidikan dan Kebudayaan Kabupaten Muna, 2011).

Keraf, Gorys. Diksi dan Gaya Bahasa, (Jakarta: PT Gramedia Pustaka Utama, 2007).

La Fariki, Nilai-Nilai Budaya dan Sejarah Daerah Muna, (Kendari: Komunika, 2011).

Lutfi Muh. Malik, Islam dalam Budaya Muna: Suatu Ikhtiar Menatap Masa Depan (Ujung Pandang: PT Umitoha Ukhuwah Grafika, 1997).

Martinich, A.P, The Philosophy of Language (Third edition), (Oxfrod: Oxfrod University Press, 1996).

Poedjosudarmo, Soepomo, Filsafat Bahasa, (Surakarta: Universitas Muhammadiyah Press, 2001).

Rahmat Sewa Suraya, "Tradisi Haroa pada Etnik Muna: Fenomena Budaya dalam Kehidupan Beragama di Era Global", dalam Jurnal Kajian Budaya,Vol. 10, No.20 (Denpasar: Program S2 dan S3 Kajian Budaya, 2016).

Ramadan, Muhammad La Ode, "Kearifan lokal di Kabupaten Muna (Dalam Pengelolaan Sumberdaya Pesisir dan Laut)", 2 September 2012 dalam https://formuna.wordpress. com/2016/09/02/kearifan-lokal-dikabupaten-muna-dalam-pengelolaansumberdaya-pesisir-dan-laut/ diakses 30 Mei 2017.

Supriyanto, dkk.. "Sejarah Kebudayaan Islam" dalam Jurnal "Al-Qalam" Volume 21 Nomor 1 Juni 2015. 